\title{
OVERVIEW
}

\section{Primate conservation: measuring and mitigating trade in primates}

\author{
V. Nijman ${ }^{1, *}$, K. A. I. Nekaris ${ }^{1}$, G. Donati ${ }^{1,2}$ M. Bruford ${ }^{3}$, J. Fa ${ }^{4}$ \\ ${ }^{1}$ School of Social Sciences and Law, Oxford Brookes University, Gipsy Lane, Oxford OX3 0BP, UK \\ ${ }^{2}$ Department of Ethology, Ecology and Evolution, University of Pisa, Via Volta 6, 56126 Pisa, Italy \\ ${ }^{3}$ Cardiff School of Biosciences, Cardiff University, Museum Avenue, Cardiff CF10 3AX, UK \\ ${ }^{4}$ Durrell Wildlife Conservation Trust, Les Augrès Manor, La Profonde Rue, Trinity, Jersey JE3 5BP, UK
}

\begin{abstract}
Trade in primates is seen as a significant impediment to their conservation. Primates are traded both domestically and internationally, in order to supply, amongst others, biomedical industries and pharmaceutical markets, the entertainment business, or pet markets. Primate meat is consumed globally, whereas body parts are used as ingredients in traditional medicine or sold as curios. All international trade in primates is regulated through the Convention on International Trade in Endangered Species of Wild Flora and Fauna (CITES), to which all but 2 primate range countries are signatory. The last 15 years has seen a linear increase in the export of live primates (each year 3500 more individuals are exported), with China being, numerically, the largest exporter. While the trade in live primates worldwide involves tens, if not hundreds, of thousands of individuals a year, the trade in dead primates involves millions of animals a year. We introduce here a series of studies dealing with various aspects of the primate trade. We hope that these studies will urge others to quantify the extent of trade in primates alive and dead in both domestic and international contexts, allowing us to find ways to mitigate the consequences of this trade to the conservation of primates.
\end{abstract}

KEY WORDS: Bushmeat · CITES · Conservation · Reintroduction · Wildlife trade

International wildlife trade is seen as one of the leading threats to biodiversity conservation (Sutherland et al. 2009). The trade in primates, be it as live individuals, as body parts or as meat has been invoked as a significant threat to their conservation (Cowlishaw \& Dunbar 2000, Mittermeier et al. 2009). Recognising the need to control this trade, the Convention on the International Trade in Endangered Species of Wild Flora and Fauna (CITES), first drawn up in 1973 and entering into force in 1976, has now been ratified by 175 countries or states. From the inception of CITES, it has been recognised that the international primate trade needs to be regulated, and indeed all species of primates are either listed in Appendix II of CITES (regulating all commercial trade) or in Appendix I (precluding all commercial trade). As of 2010, all but 2 primate Range States (Angola and possibly Timor Leste) are Party to CITES.
In December 2008 the Primate Society of Great Britain organised a conference in London entitled 'Primate conservation: measuring and mitigating trade in primates' where new data on the primate trade were presented and where its various aspects were discussed. Here we present a brief overview of the nature of the primate trade putting the different contributions to this Theme Section in context.

In the late 1960s and early 1970s the international primate trade peaked to supply the demand for the biomedical industry and pharmaceutical markets. During this period, India exported between 50000 (1960s) and 20 000 (early 1970s) primates per annum (Southwick \& Siddiqi 2001), whereas Peru exported on average 30000 primates per year (Smith 1978). These official export figures were quite possibly underestimates, and in the years which followed several countries implemented trade bans (Held \& Wofle 1994, 
Southwick \& Siddiqi 2001). Now, over 30 yr later, there seems to be a general consensus, at least among conservationists and primatologists, that the main threat to primates is habitat loss and hunting (e.g. Cowlishaw \& Dunbar 2000, Strier 2011), although trade is recognised as a leading threat for selected species (e.g. barbary macaque Macaca sylvanus [Van Lavieren \& Wich 2009] and slow lorises Nycticebus spp. [Nekaris \& Nijman 2007]). Including domestic trade, however, the live primate trade involves tens, if not hundreds, of thousands of individuals a year (see below), whereas the trade in dead primates involves millions a year (e.g. Fa et al. 2006). While one would perhaps expect that levels of trade in live primates have diminished somewhat, data from the CITES trade database (www.cites.org/eng/resources/trade.shtml) show that this is not the case (Fig. 1). Since 1995 there has been a linear increase in the export of live primates $\left(\mathrm{R}^{2}=\right.$ $89.9 \%$ ), with 3500 more individuals being exported each year. Since 1995 China (31\%) and Mauritius (18\%) supply almost half of all primates traded internationally; the single largest importer of live primates is the USA (26\%) followed by Japan (14\%) and China (13\%).

Between 1990 and 1999 the numbers of wild-caught and captive-bred primates were more or less equal; after that there was a massive increase in captivebreeding. Whether or not all these 'captive-bred' individuals are indeed derived from the wild has been questioned (e.g. Eudey 2008). Another issue is whether or not these figures represent real volumes or whether there is a significant illegal international trade in addition to that which has been reported to CITES. Eudey (2008) presented data on the large-scale illegal trade in

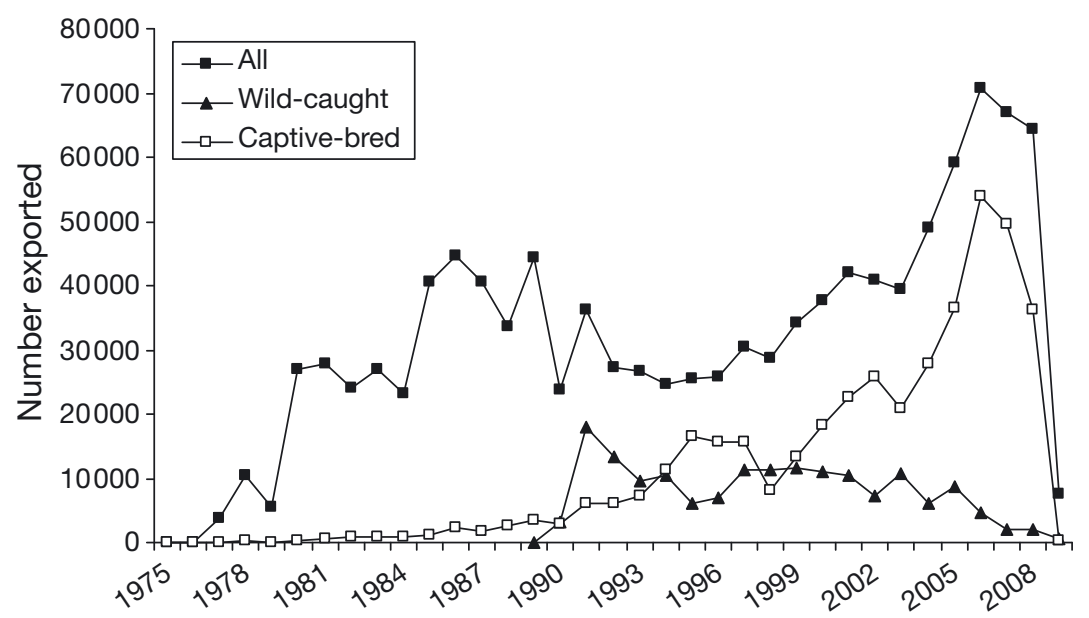

Fig. 1. Export of a total of 1.1 million live primates as reported by exporting Parties to the CITES Secretariat, showing total numbers, and the number of wildcaught and captive-bred individuals. China, the largest exporter of primates at present, joined CITES in 1980. Numbers in the early years and for 2009 (and possibly 2008) are artificially low because of under-reporting long-tailed macaques Macaca fascicularis from mainland Southeast Asia (Cambodia, Laos, Vietnam) into China, to supply the booming biomedical trade. Likewise, Maldonado et al. (2009, this Theme Section) report on the trade of over 4000 night monkeys (Aotus spp.) per annum from Peru and Brazil into Colombia to supply a biomedical research facility with primates. No records are available for night monkeys in trade from Peru and Brazil into Colombia in the CITES trade database. Data on domestic trade in primates are more difficult to acquire (cf. Mack \& Mittermeier 1984), but work presented in this Theme Section by Nijman et al. (2009) Ceballos-Mago \& Chivers (2010), CeballosMago et al. (2010) and Shepherd (2010) shows that this can involve considerable numbers.

Apart from the live primate trade, there is a significant international trade in dead primates and their derivatives. For instance, data from the CITES trade database show that in the last 30 yr 1365 primate bodies (mainly macaques and baboons), 6143 skins (colobus monkeys) and 11292 skulls (baboons and vervets) were exported. Unbeknownst to many perhaps, there exists a significant market for primates to be hunted as trophies, with almost 20000 primates (of $>32$ species) having been exported as such over the last 30 yr.

Fa et al. (2006) calculated that, of over a million carcasses traded as bushmeat per year at 100 sites, close to $15 \%$ were of primates, and Alves et al. (2010), providing an overview of the global use of primates in traditional folk medicines, noted that $>100$ species were traded for this purpose. Wright \& Priston (2010, this Theme Section) provide a case study of the bushmeat trade in Cameroon, showing that even at a local scale, capture of bushmeat for sale far exceeds that for local consumption. Starr et al. (2010, this Theme Section) quantify the dramatic impact of domestic trade on Cambodia's 2 slow loris species, demonstrating that their key role in folk medicine may be driving them towards extinction. Whereas trade in live individuals, skins and trophies is by and large attributable to individual species (or higher taxa), the trade in primate body parts or primate meat often involves unidentifiable items. Rönn et al. (2009, this Theme Section) provide a novel way to identify primates in the bushmeat trade by microarray sequencing to facilitate law enforcement.

Since 2000, the Primate Specialists Group of the International Union for the Conservation of Nature in associa- 
tion with the International Primatological Society and Conservation International have brought out a list of the World's top 25 most endangered primates. Mittermeier et al. (2006) mention trade as threatening only one of the 25 listed taxa, whereas only 4 yr on, trade for meat, medicine and pets is implicated as a major source for the decline of 9 of the world's rarest primate taxa (Mittermeier et al. 2009). We urge further studies such as those presented in this Theme Section to quantify the extent of this serious threat.

Acknowledgements. We thank the Primate Society of Great Britain for sponsoring the meeting that inspired these contributions and for funding the travel expenses of several key speakers. We are grateful to the Zoological Society of London for sponsoring the event. We thank P. Kuhn and B. Godley for their patience throughout the editorial process.

\section{LITERATURE CITED}

Alves RR, Souto WMS, Barboza RRD (2010) Primates in traditional folk medicine: a world overview. Mammal Rev 40: $155-180$

Ceballos-Mago N, Chivers DJ (2010) Local knowledge and perceptions of pet primates and wild Margarita capuchins on Isla de Margarita and Isla de Coche in Venezuela. Endang Species Res 13: 63-72

Ceballos-Mago N, González CE, Chivers DJ (2010) Impact of the pet trade on the Margarita capuchin monkey Cebus apella margaritae. Endang Species Res 12:57-68

Cowlishaw G, Dunbar RIM (2000) Primate conservation biology. University of Chicago Press, Chicago, IL

Eudey AA (2008) The crab-eating macaque (Macaca fascicularis): widespread and rapidly declining. Primate Conserv 23:129-132

Fa JE, Seymour S, Dupain J, Amin R, Albrechtsen L, Macdonald D (2006) Getting to grips with the magnitude of exploitation: bushmeat in the Cross-Sanaga rivers region, Nigeria and Cameroon. Biol Conserv 129:497-510

Held JR, Wofle TL (1994) Imports: current trends and usage. Am J Primatol 34:85-96

Mack D, Mittermeier RA (eds) (1984) The international primate trade, Vol 1. TRAFFIC, Washington, DC

Maldonado AM, Nijman V, Bearder SK (2009) Trade in night monkeys Aotus spp. in the Brazil-Colombia-Peru tri- border area: international wildlife trade regulations are ineffectively enforced. Endang Species Res 9:143-149

Mittermeier RA, Valladares-Pádua C, Rylands AB, Eudey AA and others (eds) (2006) Primates in peril: the world's 25 most endangered primates 2004-2006. Primate Conserv 20:1-28

Mittermeier RA, Wallis J, Rylands AB, Ganzhorn JU and others (eds) (2009) Primates in peril: the world's 25 most endangered primates 2008-2010. IUCN/Species Survival Commission (SSC) Primate Specialist Group (PSG), International Primatological Society (IPS), and Conservation International (CI), Arlington, VA

> Nekaris KAI, Nijman V (2007) CITES proposal highlights rarity of Asian nocturnal primates (Lorisidae: Nycticebus). Folia Primatol (Basel) 78:211-214

> Nijman V, Yang Martinez C-f, Shepherd CR (2009) Saved from trade: donated and confiscated gibbons in zoos and rescue centres in Indonesia. Endang Species Res 9:151-157

> Rönn AC, Andrés O, López-Giráldez F, Johnsson-Glans C and others (2009) First generation microarray-system for identification of primate species subject to bushmeat trade. Endang Species Res 9:133-142

> Shepherd CR (2010) Illegal primate trade in Indonesia exemplified by surveys carried out over a decade in North Sumatra. Endang Species Res 11:201-205

Smith NJ (1978) Human exploitation of terra firme fauna in Amazonia. Cienc Cult 30:17-23

Southwick CH, Siddiqi MF (2001) Status conservation and management of primates in India. In: Gupta AK (ed) Nonhuman primates of india. ENVIS bulletin: wildlife and protected areas. Wildlife Institute of India, Dehradun p 81-91

Starr C, Nekaris KAI, Streicher U, Leung L (2010) Traditional use of slow lorises Nycticebus bengalensis and N. pygmaeus in Cambodia: an impediment to their conservation. Endang Species Res 12:17-23

Strier KB (2011) Conservation. In: Campbell CJ, Fuentes A, MacKinnon KC, Bearder SK, Stumpf RM (eds) Primates in prespective, 2nd edn. Oxford University Press, Oxford p 664-675

Sutherland WJ, Adams WM, Aronson RB, Aveling R and others (2009) An assessment of the 100 questions of greatest importance to the conservation of global biological diversity. Conserv Biol 23:557-567

Van Lavieren E, Wich SA (2009) Decline of the Barbary macaque Macaca sylvanus in the cedar forest of the Middle Atlas Mountains, Morocco. Oryx 44:133-138

- Wright JH, Priston NEC (2010) Hunting and trapping in Lebialem Division, Cameroon: bushmeat harvesting practices and human reliance. Endang Species Res 11:1-12 